Original Research Paper

\title{
The Use of Nano Silica for Improving Mechanical Properties of Hardened Cement Paste
}

\author{
Intisar Kuli, Taher M. Abu-Lebdeh, Elham H. Fini and Sameer A. Hamoush \\ Department of Civil, Architectural and Environmental Engineering, \\ North Carolina A\&T State University, Greensboro, NC, USA
}

Article history

Received: 22-02-2016

Revised: 26-02-2016

Accepted: 29-02-2016

Corresponding Author:

Taher M. Abu-Lebdeh,

Department of Civil

Architectural and Environmental

Engineering, North Carolina A\&T

State University, Greensboro, NC, USA

Email: taher@ncat.edu

\begin{abstract}
The influence of adding Nano particles of silicon dioxide $\left(\mathrm{SiO}_{2}\right)$ on cement pastes was studied for both water and vacuum curing methods. Specimens made up of different percentage of Nano Silica were tested at different ages ranging from 3-56 days. The effect of (5-20 nm) Nano-Silica on the strength development of Nano-cement was determined using Material Tests System (MTS). The purpose of the study was to investigate the effect of Nano-Silica addition on the compressive strength and on the signature phase of calcium silicate hydrate during the hydration process of a cement paste. Percentage of 5 and 10\% Nano-Silica by volume of cement were used in this study and compared with $0 \%$ Nano-Silica representing control paste. The ratio of water to cementations material $(\mathrm{w} / \mathrm{c})$ for all mixtures was kept constant at 0.40 . The experimental results show that the compressive strengths of the hardened cement paste with 5\% Nano-Silica particles were all higher than those of controlled paste for both water and vacuum cured specimens. This increase in strength may be attributed to the reaction between Nano-Silica and Calcium Hydroxide $(\mathrm{CH})$ to develop more calcium silicate hydrate $(\mathrm{C}-\mathrm{S}-\mathrm{H})$ resulting in higher strength. On the contrary, the addition of $10 \%$ Nano-Silica yields lower compressive strength than the reference paste. The result also show that the vacuum cured specimens yield higher strength than the water cured specimens for up to 28 days. Nevertheless, the final strength for water cured specimens was higher than for vacuum cured specimens.
\end{abstract}

Keywords: Nano Silica, $\mathrm{SiO}_{2}$, Compressive Strength, Vacuum Curing, MTS

\section{Introduction}

To support the increasing demands for sustainability, reusing some by-products such as fly-ash, silica fume and Nano-Silica is an attractive option. In fact, several researchers have shown that the utilization of industrial by-products improves various properties of concrete and produces eco-friendly materials. Further, the use of nanotechnology has become widespread in all branches of science. For instance, concrete performance is strongly dependent on Nano-Size dimensions of material such as the Calcium Silicate Hydrates (C-S-H) particles or the gel porosity in the cement matrix (Sobolev et al., 2009). Using mineral additives such as silica fume or Nano-Silica will enhance concrete strength and durability, because of their fine particles, large surface area and high $\mathrm{SiO}_{2}$ content. However, Nano-Silica is preferred over silica fume because of its smaller particle size and higher surface area. Nano-Silica is silicon dioxide nano particles $\left(\mathrm{SiO}_{2}\right)$, synthetic product of porous and nearly spherical particles, with great potential advantages especially in glass and concrete industries. The size of its particles are extremely small, approximately $1 / 100$ th the size of cement particle. NanoSilica particles, according to their structure, are divided into two types: P-type (Porous particles) and S-type (Spherical particles). P-type Nano-Silica surface contains a number of Nano-porous with the pore rate of 0.611 $\mathrm{ml} / \mathrm{g}$; therefore, P-type has much larger surface area comparing to the S-type (USRNI, 2015).

There are many properties affected by Nano-sized particles such as strength, durability and permeability. 
Nano-Silica have a little pozolanic properties when react with the calcium hydroxide (by-product of the reaction of cement and water) and forming calcium silicate hydrate as a major product and calcium hydroxide as by product. The reaction of these additives will form more $\mathrm{C}-\mathrm{S}-\mathrm{H}$ which is a gel or binder that holds all materials together and result in the strength of concrete material. Calcium silicate hydrate is the main hydration product and the main source of the concrete strength. It is often abbreviated as "C-S-H". The ratio of $\mathrm{SiO}_{2}$ to $\mathrm{CaO}$ is inferred, the $\mathrm{Si} / \mathrm{Ca}$ ratio is variable but approximately 0.45-0.50 in hydrated Portland cement. In the presence of additives such as fly ash, silica fume and Nano-Silica, this ratio increase perhaps up to 0.6. Further, the inclusion of the additive materials will act like fillers. They fill the voids in the cement paste. Since NanoSilica is about 100 times smaller than cement, it can fill the pores in cement paste resulting in denser and more impermeable texture (Maheswaran et al., 2013).

Effect of Nano-Silica on compressive strength and other properties of the cement paste has been studied by several researchers. Maheswaran et al. (2013) reported that the addition of Nano-Silica in normal strength mortar increased the compressive strength and early hydration of cement mortar which is attributed to pozzolanic nature of Nano-Silica. They indicated that the reaction of Nano-Silica with excess $\mathrm{CH}$ during cement hydration has led to reduction in calcium hydroxide content and thus resulted in reduction in chemical leaching of $\mathrm{CH}$ and sulfate attack and enhancement of the delay in development of micro crack. Thus, the presence of Nano-Silica works on two directions, the first one is the chemical effect (pozzolanic reaction) of silica with calcium hydroxide which forms more C-S-Hgel and the reduction in the calcium hydroxide which provides evidence of pozzolanic reaction. The physical effect results because Nano-Silica is about 100 times smaller than cement. It can fill the voids in the cement paste resulting in denser and more impermeable texture of mortar. Ye Qing et al. (2007) reported that the compressive strength increases with the increase in replacement percentage. Their experiments used an addition of $0,1,2,3$ and $5 \%$ of Nano-Silica to cement replacement by mass. Their results show great improvement in compressive strength at all ages of testing. Signifying 5\% of cement replacement was the optimum. Bagheri et al. (2013) found similar results and concluded that optimum content is $5 \%$ and further increase doesn't show further improvement. Jonbi et al. (2012) reported that adding Nano-Silica with 5\% replacing of cement by weight showed higher compressive strength up to 28 days. However, higher percentages of replacing such as $10 \%$ didn't have further effect. Also they reported that highest 28-day compressive strength was obtained from $10 \%$ Nano-
Silica $+5 \%$ silica fume. The inclusion of silica fume caused substantial reduction in penetration rate of chlorides through reduction of pore connectivity of the mixture. Elkady et al. (2013) carried out a thorough experimental investigation on the main reasons for the inconsistencies of reported results in workability and compressive strength of Nano-Silica concrete. They concluded that the addition of super plasticizer increases compressive strength of modified cement by $26 \%$ compared to the controlled specimens. Researchers as Collepardi et al. (2004) reported that up to 28 days the compressive strength of conventional concrete was larger than that of concrete blended with Nano-Silica. However; the final results indicated that the addition of Nano particles improves the properties of concrete. Zaki and Ragab (2000) conducted testing using 0, 0.5, 0.7 and $1 \%$ of Nano-Silica in concrete along with $20 \%$ of silica fume in all mixes. They concluded that the optimum amount of Nano-Silica was $0.5 \%$ by weight of cementitious material.

\section{Experimental Program}

\section{Methodology}

The objective of this research work was to study the merits of introducing Nano-Silica to cement paste by investigating the effects of Nano-Silica on the compressive strength of the hardened Nano Silica-cement paste. Specimens of different amounts of Nano-Silica ( 0,5 and $10 \%)$, cured by different curing method (water cured and vacuum seal cured) were tested at different ages $(3,7,14,28,56$ days). Approximately 90 specimens of 4 in. by 8 in. cylinders and 90 specimens of 2 in. cubes were prepared, cured and tested utilizing Forney and MTS testing machines. Half of the specimens were cured in water while the other half in vacuum.

\section{Materials}

The cementitious material used in this study were Type 1 Portland cement that complies with ASTM C150 and with the Federal specifications SS-C-1960/3; and Nano-Silica obtained from Sky Spring Nano materials, Inc., Houston- Texas (shown in Fig. 1). The particle sizes of the Nano-Silica ranges from 15-20 nm. The chemical analysis of the cementitious materials is tabulated in Table 1. It can be seen that the Nano-Silica material consists mostly of pure silica $(>99 \%)$. Table 2 shows the physical properties of the Nano-Silica.

Three different mix proportions were designed. The first mix, M1, was the control mix with cement and water. The remaining mixes, M2 and M3 consisted of 5 and $10 \%$ Nano Silica by volume of cement, respectively. The water to cement $(\mathrm{w} / \mathrm{c})$ ratio was 0.40 for all mixes. For each of the three percentage, three $(4 \times 8)$ cylinders 
and three cubes were created for each curing method and age of testing. Testing conducted at 3, 7, 14, 28 and 56 days. The cylinders were comprised of plastic molds, 4 inches in diameter and 8 inches in depth and in compliance with ASTM C-470. The cubes were formed in brass molds, exactly 2 inches. Mixing procedures start by weighing the dry cement and Nano-Silica and then dry mixed together by hand. The water was added into the Hobart mixing bowl and then the dry mixed materials were add and mixed together. The Hobart HL 200 mixer was used for all mixes where the materials were mixed at a low rate (59 agitator $\mathrm{rpm}$ ) for $30 \mathrm{sec}$ then the rate was increased to Level 1 (107 agitator rpm) for all additional minute. After finishing mixing, the mixture was poured into the cylinders and cube molds.
The cylinders and cubes were rodded, vibrated, leveled and then stored away for $24 \mathrm{~h}$. After this, the specimens were demoded and cured either in water or vacuum until the day of testing.

\section{Testing Equipment}

The cylinder compressive strength was conducted using the 400 kip load capacity Forney testing machine, operated at a load rate of $12,000 \mathrm{lbs} / \mathrm{min}$. The stressstrain curves were obtained by testing the 2 inches cube specimens using MTS 810 Landmark Servo hydraulic Testing system. The system includes MTS software, Flex Test controls, MTS servo hydraulic technology and a complete selection of accessories (Fig. 2).

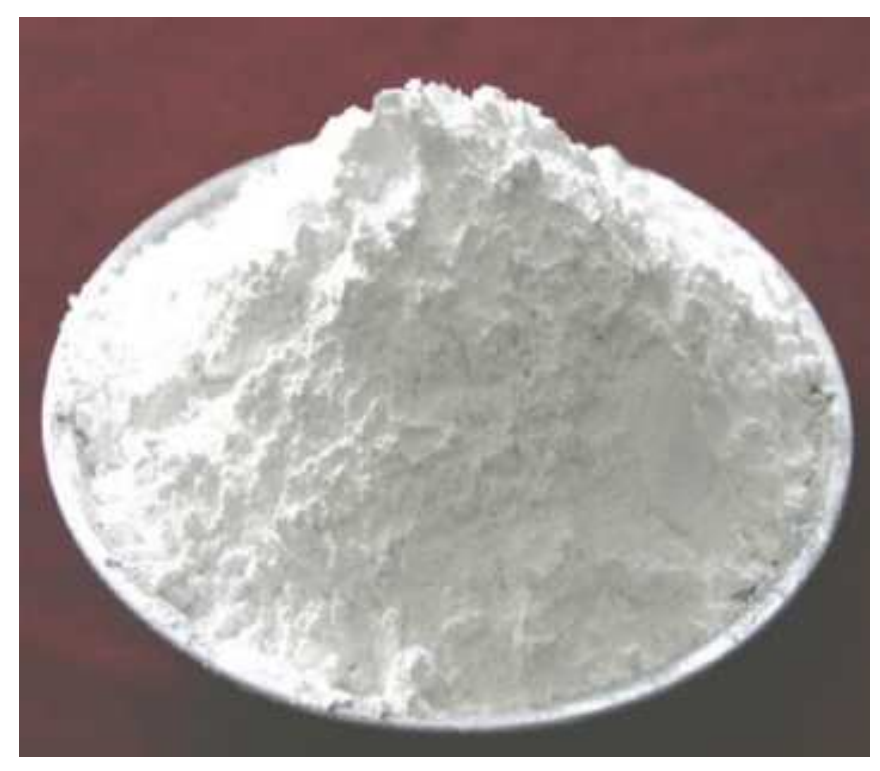

Fig. 1. Image of Nano-Silica

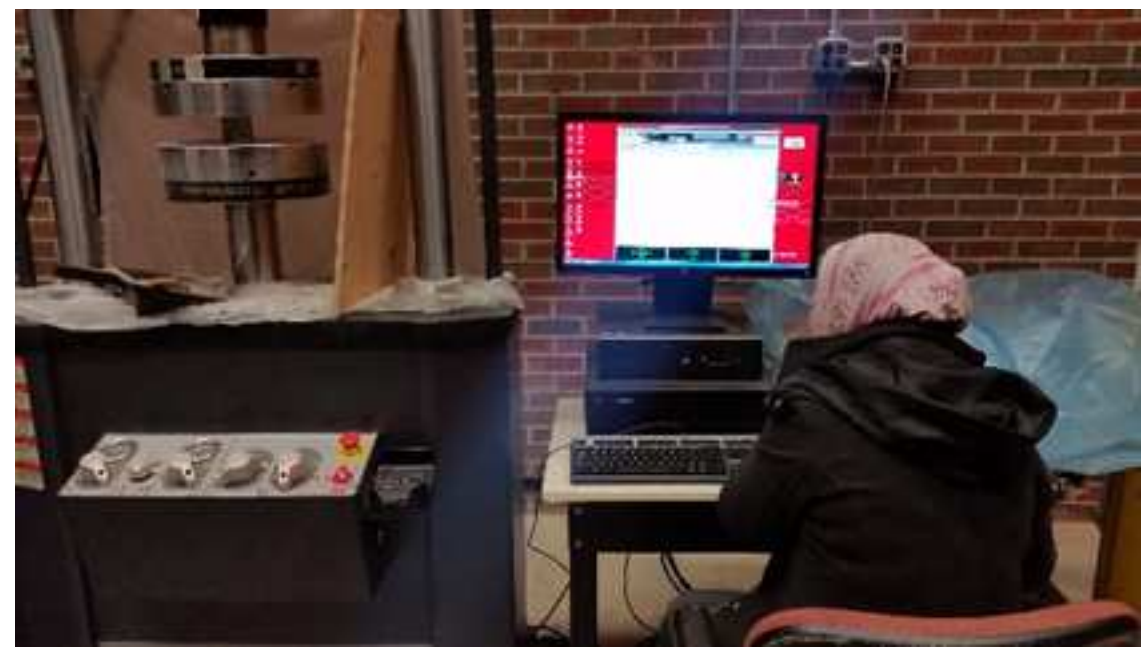

Fig. 2. MTS 810 testing system 
Table 1. Chemical composition-cementitious materials

\begin{tabular}{lcc}
\hline Percentage (\%) & Portland cement & Nano-silica \\
\hline $\mathrm{SiO}_{2}$ & 20.20 & 99.5 \\
$\mathrm{Al}_{2} \mathrm{O}_{3}$ & 4.80 & - \\
$\mathrm{CaO}$ & 64.30 & - \\
$\mathrm{MgO}$ & 1.20 & - \\
$\mathrm{Fe}_{2} \mathrm{O}_{3}$ & 3.20 & - \\
$\mathrm{Na}_{2} \mathrm{O}$ & 0.49 & - \\
$\mathrm{K}_{2} \mathrm{O}$ & 0.31 & - \\
$\mathrm{SO}_{3}$ & 2.90 & - \\
$\mathrm{LOI}$, loss of ignition & 1.30 & - \\
\hline
\end{tabular}

Table 2. Physical properties of the nano silica

\begin{tabular}{ll}
\hline Description & Results \\
\hline Particle size $(\mathrm{nm})$ & $15-20$ \\
Surface area $\left(\mathrm{m}^{2} / \mathrm{g}\right)$ & 640 \\
Bulk density $\left(\mathrm{g} / \mathrm{cm}^{3}\right)$ & $0.08-0.10$ \\
Molecular & $\mathrm{SiO}_{2}$ \\
Molecular weight & 60.08 \\
Porosity $(\mathrm{ml} / \mathrm{g})$ & 0.6 \\
Morphology & Porous and nearly spherical \\
\hline
\end{tabular}

\section{Results}

\section{Compressive Strength and Stress-Strain}

The 400 kip capacity Forney testing machine was used to carry out cylinder compressive strength tests. Testing results are tabulated in Table 3 . The table shows the average compressive strengths for all water and vacuum cured specimens tested at 3, 7, 14, 28 and 56 days. As shown, for both curing methods the 5\% Nano silica samples performed significantly higher than that of the controlled. The 14 days strengths show irregular results for both strength and stressstrain curves, although different testing machines were used. To compare the cylinder compressive strengths of the reference curing methods, a separate column graph was created to represent the comparison. Results also show that the water curing samples produced higher compressive strength at 56 days than that of the vacuum cured samples.

Stress-strain curves were obtained for each of the ninety (90) hardened cement paste cube tested in the MTS machine. As stated earlier in the experimental procedure, three different percentage (control 0, 5 and $10 \%$ ) of Nano Silica were used in the study. For each percentage, three cubes for water curing and three for vacuum curing were cast for each age of testing. The stress-strain curves obtained from the three cubes were averaged together to obtain a single averaged stress-strain curve. Although, several graphs were developed to display the effect of age and curing methods with the change in $\% \mathrm{NS}$ content, the following stress-strain curves display partial results, Fig. 3 displays the stress-strain curves for the control samples cured in water at all ages. It can be seen that there is an increase in strength from the 3 day tests, up to 56 day tests. Figure 4 shows the stress-strain curves for the control specimens cured in vacuum for five different curing ages. Similar to the results from the water cured data, the results display an increase in strength from the 3 day curing up to the 56 day curing. As seen in these Fig. 3 days compressive strengths were about 6000 psi for specimens cured in water and approximately 5000 psi for vacuum cured specimens. At 56 day curing, the strength increased to about 13,000 psi and 12,000 psi for water curing and vacuum curing, respectively.

Figure 5 displays the stress-strain curves for the 5\% Nano-Silica specimens cured in water at all ages. Comparing Fig. 3 and 5, there is an increase in strength at all ages with the introduction of 5\% Nano-silica. The stresses at all testing ages are shown to be greater than that of the control specimens. The stresses for the $5 \%$ Nano-Silica specimens range between 7.1-14.4 ksi for the ages between 3-56 days. Figure 6 compares the stress-strain curves for specimens made up of different percentages of Nano Silica (0, 5 and 10\%) that were cured in water and tested after 56 days. The figure displays that 5\% Nano-Silica shows higher improvement in compressive strength compared to $10 \%$ NS. Thus, higher percentages of replacement didn't display higher improvement. The result of this study was consistent with the result from other studies such as (Bagheri et al., 2013).

Figure 7-9 illustrate the effect of curing method on stress-strain curves. For instance, Figure 7 shows the stress-strain curves for vacuum cured specimens made up of 0,5 and $10 \%$ NS and tested at 28 days. Figure 8 is similar to Fig. 6 but for specimens that were cured in water. Figure 9 combines both figures for better comparison. As shown, the maximum stress obtained from specimens cured in vacuum for 28 days were higher than the stress obtained from specimens cured in water for the same ages except for the controlled $(0 \%)$ specimens. However; at 56 days all the specimens cured in water displayed higher stress for all ages including the controlled specimen. Figure 10 illustrates the effect of curing methods and age for different percentage of Nano-Silica. 


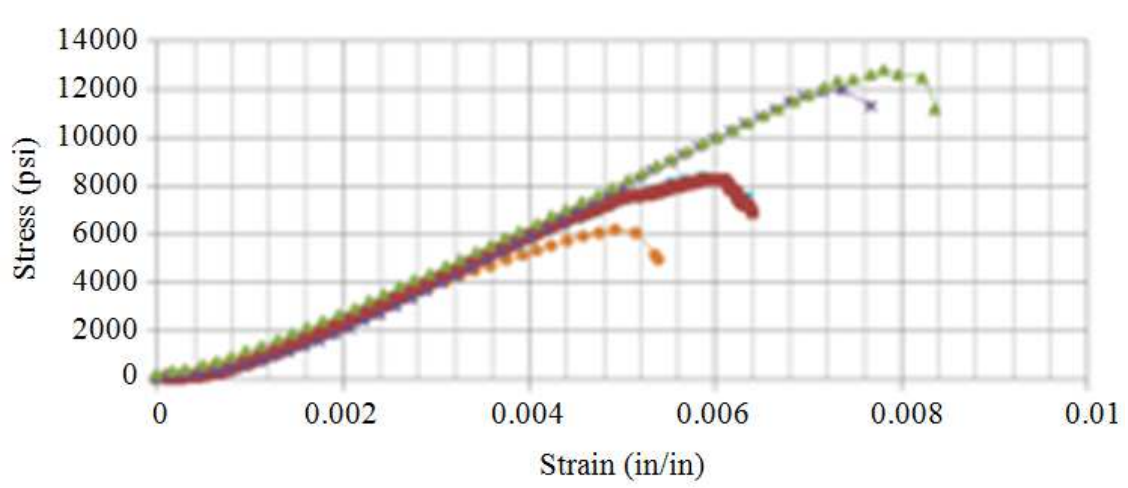

—3 Day —7 Day —14 Day —28 Day —56 Day

Fig. 3. Stress-Strain curves for the control samples cured in water at all ages

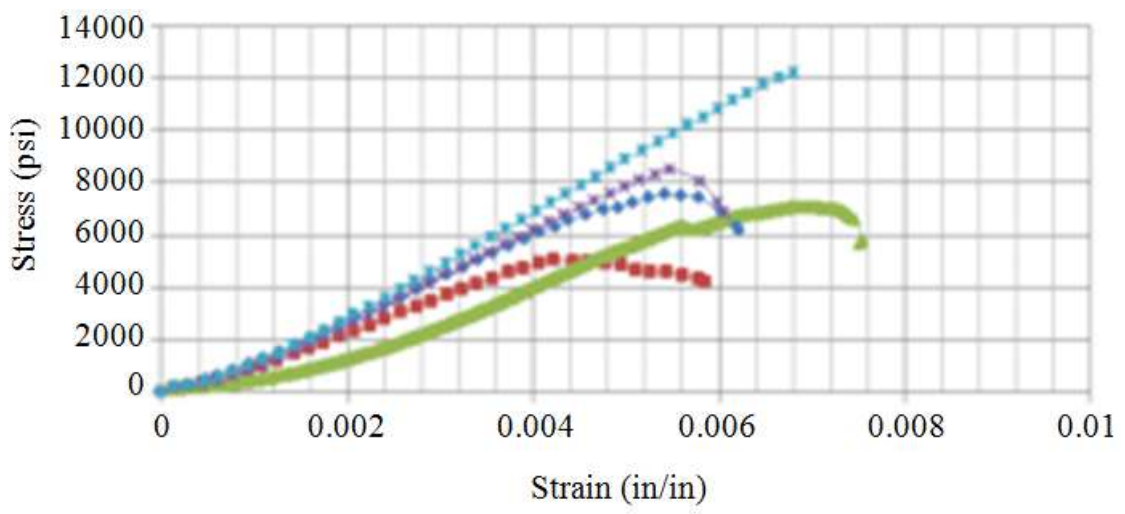

$\rightarrow 3$ Day $\rightarrow 7$ Day $\rightarrow 14$ Day $\longrightarrow 28$ Day $\rightarrow 56$ Day

Fig. 4. Stress-Strain curves for the control samples cured in vacuum at all ages

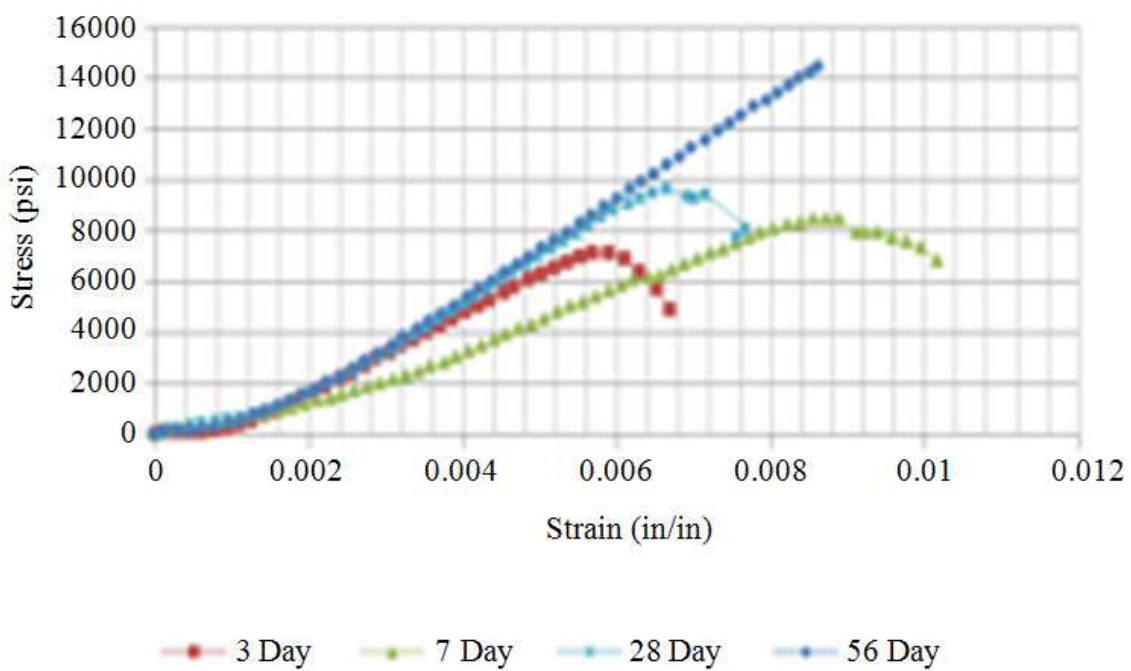

Fig. 5. Stress-Strain curves for the 5\% NS samples cured in water at all ages 


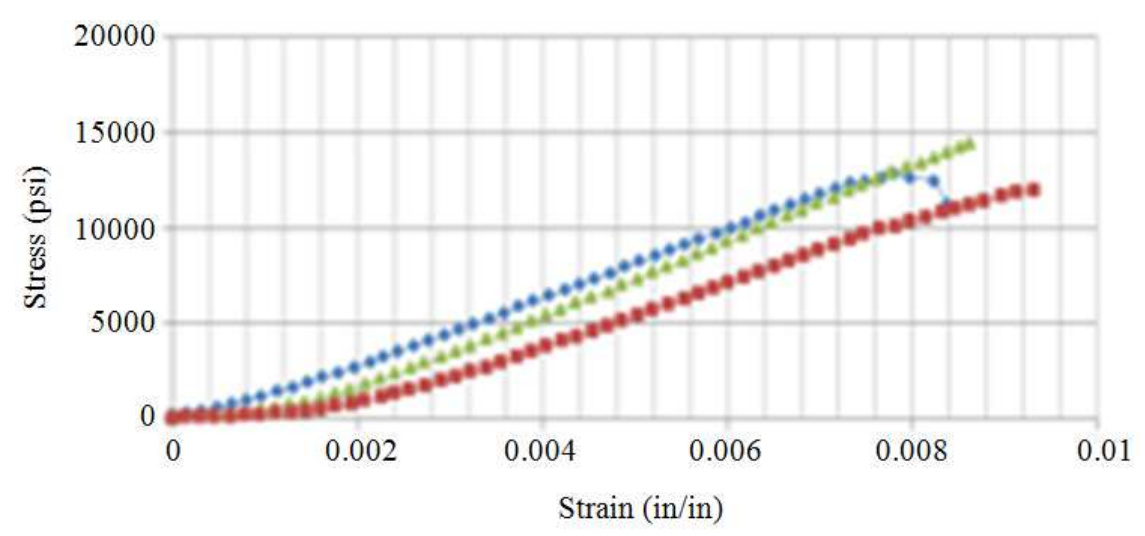

$\rightarrow 0 \% \mathrm{NS} \rightarrow 5 \% \mathrm{NS} \rightarrow 10 \% \mathrm{NS}$

Fig. 6. Stress-Strain curves for 0,5 and $10 \%$ NS samples cured in water, tested at 56 days

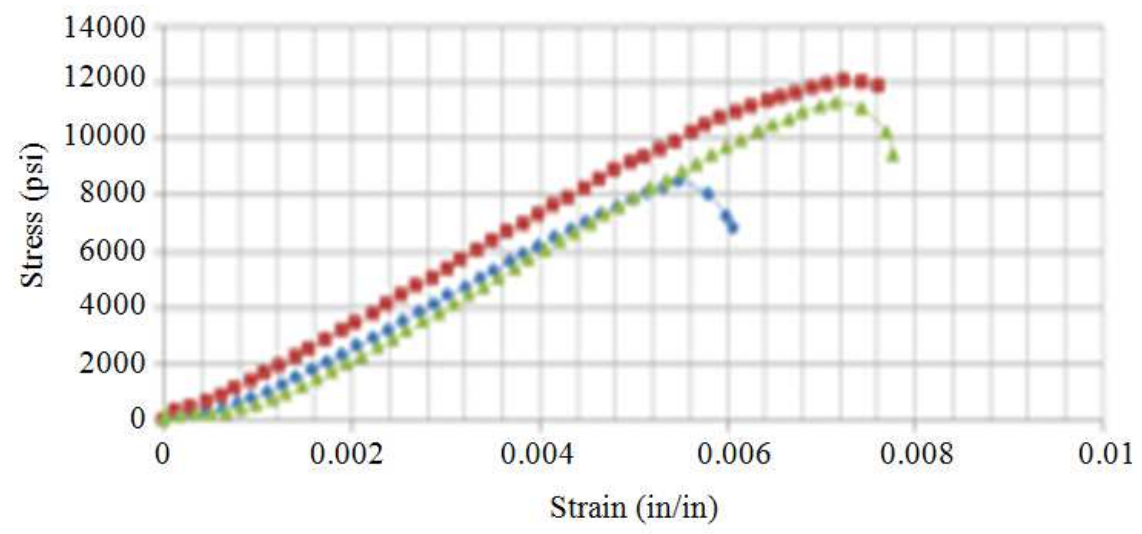

$$
\rightarrow 0 \% \mathrm{NS} \rightarrow 5 \% \mathrm{NS} \rightarrow 10 \% \mathrm{NS}
$$

Fig. 7. Stress-Strain curves of 0,5 and $10 \%$ NS specimens cured in vacuum for 28 days

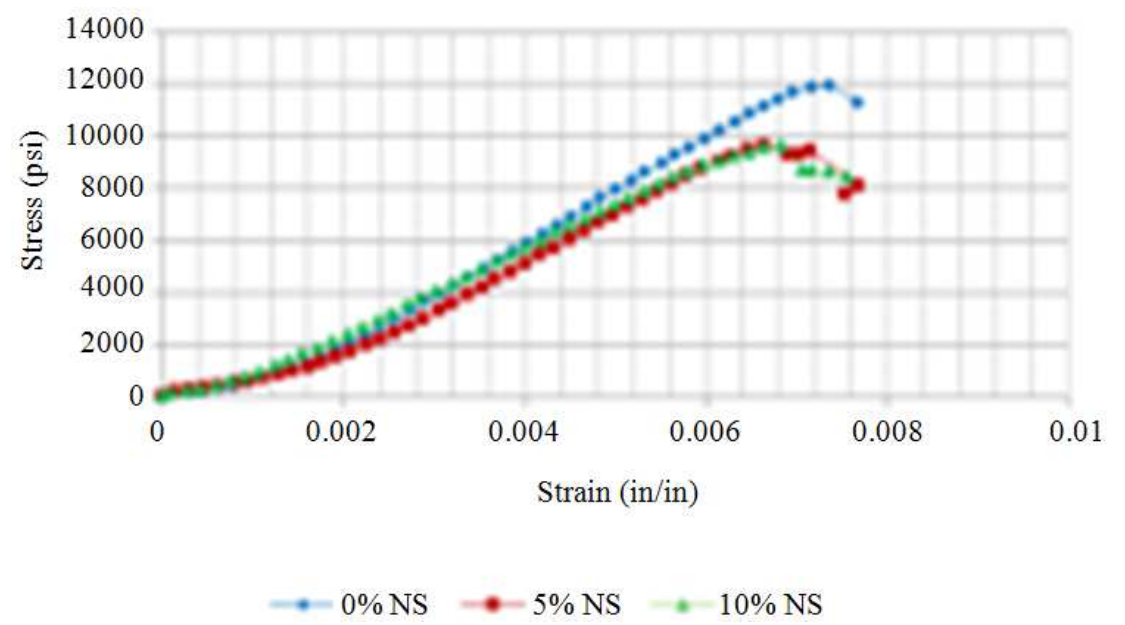

Fig. 8. Stress-Strain curves of 0,5 and $10 \%$ NS specimens cured in water for 28 days 


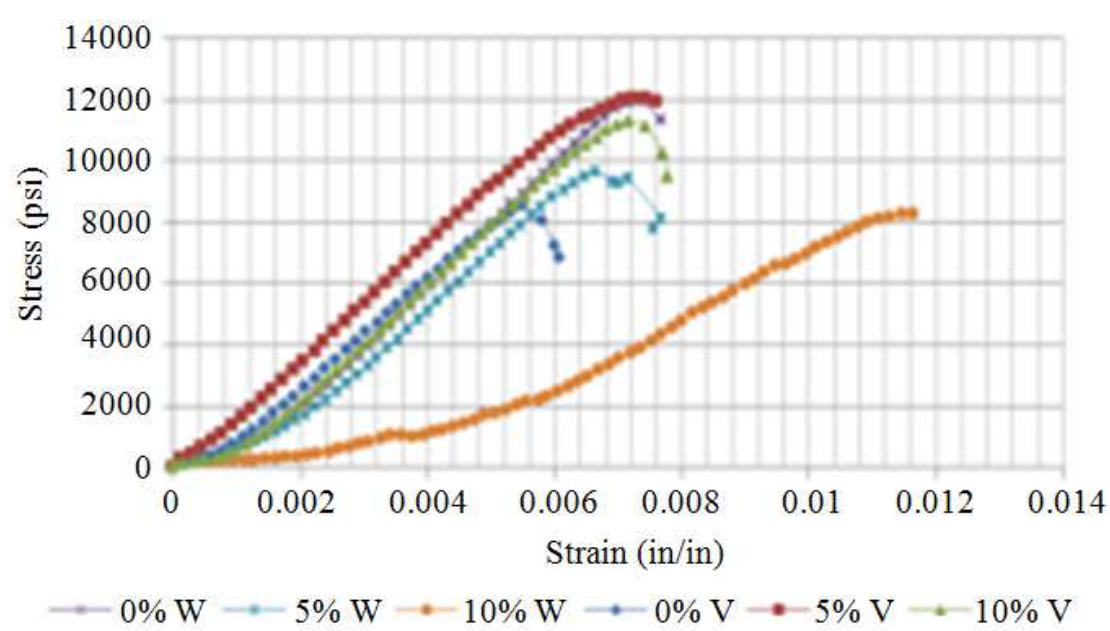

Fig. 9. Stress-Strain curves of 0,5 and $10 \%$ NS specimens cured in water and vacuumfor 28 days

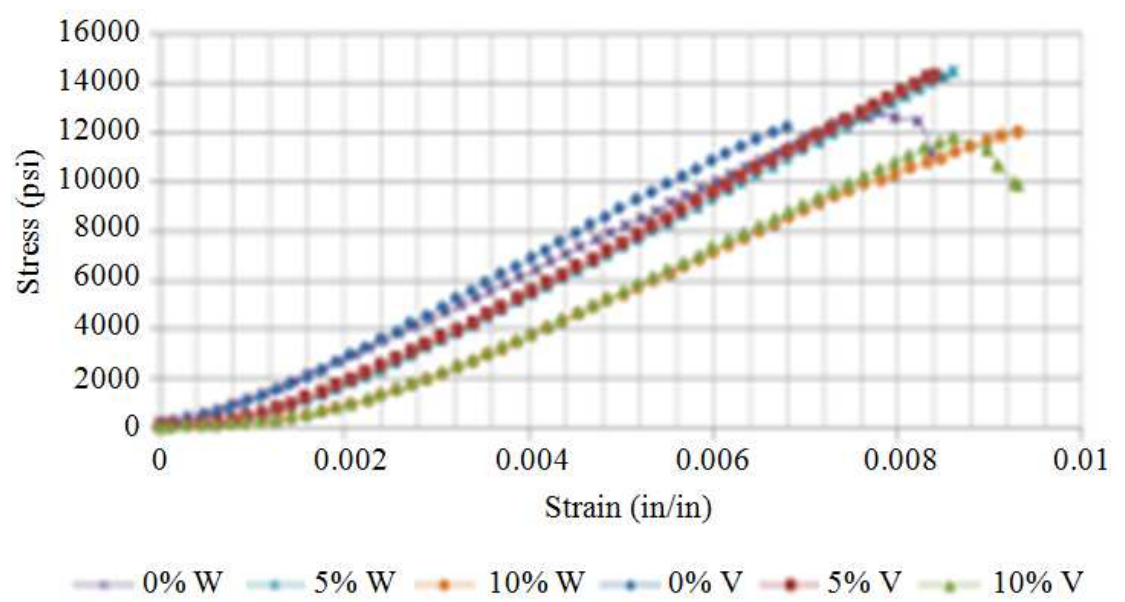

Fig. 10. Stress-Strain curves of 0,5 and $10 \%$ NS specimens cured in water and vacuum for 56 days

Table 3. Average compressive strength (psi)

\begin{tabular}{|c|c|c|c|c|c|}
\hline \multicolumn{6}{|c|}{ Water cured } \\
\hline$\% \mathrm{NS} /$ Age & 3 & 7 & 14 & 28 & 56 \\
\hline $0 \%$ & 6149 & 8377 & 8234 & 11921 & 12793 \\
\hline $5 \%$ & 7130 & 8465 & 6814 & 9650 & 14432 \\
\hline $10 \%$ & 7172 & 8710 & 5432 & 8266 & 11970 \\
\hline \multicolumn{6}{|c|}{ Vacuum cured } \\
\hline $0 \%$ & 5070 & 7542 & 7031 & 8526 & 12219 \\
\hline $5 \%$ & 8138 & 12032 & 12242 & 12039 & 14333 \\
\hline $10 \%$ & 8293 & 5274 & 10991 & 11285 & 11777 \\
\hline
\end{tabular}

\section{Discussion}

\section{Compressive Strength and Stress-Strain}

Compressive strength and stress-strain relationship were evaluated by testing specimens made up of $0 \%$ (control specimens), 5 and $10 \%$ Nano-Silica cured in water and vacuum for $3,7,14,28$ and 56 days. The control specimens were used as a reference in studying the effect of Nano-Silica and methods of curing. The reference specimens display a steady increase in strength over the course of time. For the 3 days results, the reference cement paste peaked at 6,149 psi for water cured and 5,070 psi for vacuum cured. The reference concrete strength continued to increase with time up to the 56 day test; in which the strength peaked at 12,793 psi and 12,219 psi for water and vacuum curing, respectively. 
Table 4. Percent change in strength of vacuum/water

$\%$ Change in strength

\begin{tabular}{llllll}
\hline$\%$ NS/Age & $3(\%)$ & $7(\%)$ & $14(\%)$ & $28(\%)$ & $56(\%)$ \\
\hline Control & -18 & -10 & 42 & -15 & -28 \\
$5 \%$ & 14 & -40 & 102 & 24 & -1 \\
$10 \%$ & 16 & & 37 & -2 \\
\hline
\end{tabular}

With the addition of Nano-Silica, vacuum cured specimens showed a significant increase in comparison to that of the reference material at all stages of hydration. Specimens with the addition of 5 and $10 \%$ of Nano-Silica performed approximately double the strength of the control specimens at 7, 14, 28 day vacuum cured. At 56 day, 5\% Nano-Silica specimens display $17 \%$ increase in strength; however $10 \%$ display decrease in strength compared to control specimens. For 5\% Nano-Silica replacement cured in water, the results show increase in strength for 3, 7, 56 day and decrease for 14 and 28 day comparing with the control specimens. For $10 \% \mathrm{NS}$, the results show increase in strength for 3, 7 day and decrease for 14, 28 and 56 days. The results indicate that the optimum percentage of Nano- Silica is that of the $5 \%$, due to its consistency of higher strength during all testing ages. Other researchers found the optimum between $1-3 \%$ by weight or close to $5 \%$ by volume.

The two curing methods examined in this study were the generally used water curing and a new curing method of vacuum sealing. In this section, the results of the two curing methods were compared in term of compressive strength to better understand the effects of vacuum curing on the hydration process. Relative to the control specimens, the vacuum cured specimens were weaker in strength at all ages in comparison with water curing. For $5 \%$ modified specimens, the vacuum cured specimens, performed stronger in strength in all testing ages except for 56 day specimens. While $10 \%$ NS improved strength for 14 and 28 day specimens, but decreased the 7 and 56 day strength compared to water cured specimens, yet, the strength was not too far apart. The water cured reference specimens ranged from 6,149 psi to 12,793 psi, from 3 day to 56 day. The vacuum cured reference specimens ranged between 5,070 psi to 12,219 psi, from 3 day to 56 day. In the cases that involve the incorporation of Nano-Silica, results showed increase in strength with the 5 and $10 \%$ of cement replacement. According to the results obtained from MTS machine, the optimum Nano-Silica to cement replacement for vacuum and water curing is $5 \%$. Table 4 shows the changes in strength in regards to the curing method. Values in this table represent the increase or decrease in strength of vacuum cured specimens in comparison with water cured specimens. In the control case for instance, the decrease in strength of the vacuum cured is consistent.
While for the 5 and $10 \%$ Nano-Silica replacements the increase in strength of vacuum cured specimens is dominate however, the 56 day results show a decrease in strength of the vacuum cured specimens relative to the water cured specimens.

\section{Conclusion}

The mechanical properties of the hardened Portland cement paste mixed with Nano-Silica additives have been investigated. The compressive strengths and stressstrain relations of the hardened cement pastes at 5 different stages of curing were determined and recorded for analysis by using different testing machines. The following conclusions can be drawn from the results:

- Compressive strength of cement paste increased with the increase of Nano-Silica in cement paste up to $5 \%$, further increase in percentages of NanoSilica didn't show further improvement in compressive strength

- Water curing proved to be the valuable form of curing by showing higher overall strength values than that of the vacuum cured method for control specimens

- Vacuum curing method proved to be valuable for modified cement with all percentages of replacing up to 28 day. However 56 day results proved that water cured is better than vacuum cured method

\section{Acknowledgment}

This paper summarizes the findings of a research work supported in part by the National Science Foundation (NSF). Any findings, conclusions and recommendations expressed in this paper are those of the authors.

\section{Funding Information}

The work reported here was financially supported by the National Science Foundation (NSF).

\section{Author's Contributions}

Intisar Kuli: Participated in all experimental testing, data-analysis and contributed to the writing of the manuscript. 
Taher M. Abu-Lebdeh: Participated in experimental plan and testing, data-analysis and contributed to the writing of the manuscript.

Elham H. Fini and Sameer A. Hamoush: Participated in experimental plan, data-analysis and contributed to the writing of the manuscript.

\section{Ethics}

The authors would like to disclose that Dr. Taher M. Abu-Lebdeh (Co-author) is a member of the editorial board for the American Journal of Engineering and Applied Sciences.

\section{Reference}

Bagheri, A., H. Zanganeh, H. Alizaden, M. Shakerinian and M. Marian, 2013. Comparing the performance of fine fly ash and silica fume in enhancing the properties of concretes containing fly ash. Construct. Build. Mater., 47: 1402-14082. DOI: 10.1016/j.conbuildmat.2013.06.037

Collepardi, M., S. Collepardi, U. Skarp and R. Troli, 2004. Optimization of silica fume, fly ash and amorphous nano-silica in superplasticized highperformance concretes. Int. Conf., 221: 495-506.

Elkady, H., M.I. Serag and M.S. Elfeky, 2013. Effect of nano silica de-agglomeration and methods of adding super-plasticizer on the compressive strength and workability of nano silica concrete. Civil Environ. Res., 3: 21-34.
Jonbi, I. Pane, B. Hariandja and I. Imran, 2012. The use of nanosilica for improving of concrete compressive strength and durability. Applied Mechan. Mater., 204-208: 4059-4062.

DOI: 10.4028/www.scientific.net/AMM.204-208.4059

Maheswaran, S., B. Bhuvaneshwari, G.S. Palani, R. Nagesh and S. Kalaiselvam, 2013. An overview on the influence of nano-silica in concrete and a research initiative. Res. J. Recent Sci., 2: 17-24.

Sobolev, K., I. Flores, L.M, Torres-Martinez, P.L. Valdez and P.L. Zarazua et al., 2009. Engineering of $\mathrm{SiO}_{2}$ nanoparticles for optimal performance in nano cement-based materials. Nanotechnol. Construct., 3: 139-148. DOI: $10.1007 / 978-3-642-00980-818$

USRNI, 2015. Silicon Oxide Nanoparticles Certificate of Analysis-Silicon Oxide Nanopowder $/ \mathrm{SiO}_{2}$ Nanoparticles. US Research Nanomaterials, Inc.

Ye Qing, Y., Z. Zenan, K. Deyu and C. Rongshen, 2007. Influence of nano- $\mathrm{SiO}_{2}$ addition on properties of hardened cement paste as compared with silica fume. Construct. Build. Mater., 21: 539-545. DOI: 10.1016/j.conbuildmat.2005.09.001

Zaki, I. and K. Ragab, 2009. How nanotechnology can change concrete industry. Proceedings of the International Conference Sustainable Built Environment Infrastructures in Developing Countries, (IDC' 09), pp: 2170-0095. 